\title{
Improving the efficiency of technological units for the production of high-quality motor fuels using fuzzy mathematics methods
}

\author{
Batyr Orazbayev ${ }^{1, *}$, Ainur Zhumadillayeva ${ }^{1}$, Shynar Kodanova ${ }^{2}$, Sandugash Iskakova $^{2}$, and Kulman Orazbayeva ${ }^{3}$ \\ ${ }^{1}$ Department of Systems Analysis and Control, L.N.Gumilyov Eurasian National University, Nur-Sultan, Kazakhstan \\ ${ }^{2}$ Faculty of Information Technology, Atyrau Oil and Gas University, Atyrau, Kazakhstan \\ ${ }^{3}$ Department of Management, Kazakh University of Economics, Finance and International Trade, Nur-Sultan, Kazakhstan
}

\begin{abstract}
This paper investigates the problems of increasing the efficiency of technological installations of oil refineries, which produce high-octane and environmentally friendly motor fuels. We used methods of mathematical modeling and fuzzy mathematics to maximize the volume of gasoline produced and improve its quality indicators, taking into account the imposed restrictions. On the basis of a systematic approach, an effective methodology is created for the development of a package of models of interconnected plant units using available information of a different nature, including fuzzy information. The resulting package of models makes it possible to systematically simulate the work of the unit under study and to increase the efficiency of the facility by increasing the volume of manufactured target products and improving its quality indicators. There are presented results of the analysis and expert assessment of the catalytic reforming unit LG-35-11/300-95 and the choice of the optimal type of model for individual units. A scheme is being created for combining the developed models into a single package of models. On the basis of the proposed methodology, hybrid models are being developed that make it possible to determine the volume of produced catalyzate and its quality indicators.
\end{abstract}

\section{Introduction}

In oil refinery factories for the production of high-quality motor fuels that meet modern environmental requirements, thermocatalytic processes are currently used, which take place in catalytic cracking and reforming units in the presence of catalysts $[1,2]$. Such technological installations are related to economic and ecological systems [3]. This is due to the fact that in the course of their work they produce petroleum products in demand on the world market (higher quality motor gasolines, household gas and raw materials for petrochemical synthesis), i.e. determines the economics of production. In addition, they also negatively affect the natural environment during operation, i.e. on the ecological state of the environment, throwing out various wastes. Since the technological units of catalytic cracking and reforming have various interconnected technological units in their compositions, they belong to complex chemical technological systems (CTS). In addition, many technological units for cracking and reforming operate under conditions of a deficit and unclear initial information about their states.

The lack or absence of initial quantitative information about the operation of complex chemical engineering systems is associated with the difficulty of measuring some technological parameters. Also and can be caused due to the shortage, low reliability or lack of measuring instruments in production conditions. All this significantly complicates the research and development of mathematical models and the optimization and control of traditional mathematical methods [4, 5]. But in practice, such quantitatively difficult to describe CTS are rather effectively controlled by experienced technologists, a human operator due to their knowledge, experience and intuition, which are expressed in natural language, i.e. is fuzzy information [6]. In this regard, the tasks of formalizing and using fuzzy information, which is the experience and judgments of a human operator, who in practice are a decision maker and an expert, have become very relevant for the optimization and management of such chemical engineering systems. This led to the emergence and development of a promising direction in science and technology - a fuzzy approach to modeling, optimization and management of complex quantitatively difficult to describe chemical engineering systems based on expert assessment methods and fuzzy set theories [7-10].

It should be noted that one of the urgent tasks of oil refining and the economy of the Republic of Kazakhstan is to increase the depth of oil refining and increase the production of high-quality motor fuels. The importance of this problem is also justified by the fact that currently there is a great demand for high-quality and environmentally friendly motor fuels in the domestic and world markets. In connection with the increasing environmental requirements for motor fuels, the relevance of the production of high-quality gasoline that

\footnotetext{
* Corresponding author: batyr_o@mail.ru
} 
meets the requirements of environmental standards and regulations is growing even higher. The most effective approach to solving the above problem in the conditions of catalytic cracking and reforming units operated at the refineries of Kazakhstan is the use of modern methods of mathematical modeling in a fuzzy environment $[11,12]$. The developed mathematical models of technological objects for the production of petroleum products in a fuzzy environment and modern methods of multi-criteria optimization make it possible to create a computer system for efficient control of the processes of production of high-quality motor fuel [13-16].

Approaches to the development of mathematical models of objects, which are characterized by the indistinctness of the initial information, have been investigated and proposed in works [6, 9, 11, 17]. But in these and other analyzed works on modeling complex objects in a fuzzy environment, the issues of developing a system of mathematical models of interconnected technological units have not been investigated. Since many CTS consists of interconnected technological objects, it is necessary to investigate and solve the problems of constructing a complex of interconnected models of individual CTS units and its system modeling. In this regard, this work is devoted to the development of a methodology for constructing a package of mathematical models of interconnected CTS units, i.e. system modeling of complex systems in a fuzzy environment is of theoretical and practical importance.

The main goal of this work - to determine the development of an approach to the construction of mathematical models of interconnected technological objects of a catalytic reforming unit using the initial fuzzy information. Using the developed mathematical models, i.e. on the basis of computer simulation of various operating modes of the catalytic reforming unit, it is possible to determine such ratios of input and operating parameters that provide the optimal operating mode of the unit. At the same time, the optimal operating mode of the catalytic reforming unit ensures the maximum volume and high quality of the produced motor fuel, i.e. high-octane and environmentally friendly gasoline.

\section{Materials and methods}

As a specific technological unit for the production of high-quality mother fuel, this work considers a catalytic reforming unit of the LG-35-11/300-95 model operating at the Atyrau oil refinery factory. The issues of improving the efficiency of the catalytic reformineg unit under study are investigated and solved using modern mathematical methods and methods of fuzzy mathematics. [6-11, 14-17].

The catalytic reforming unit LG-35-11/300-95 of the AtyrauRefinerywas commissioned in 1971 with a design feedstock capacity of 300 thousand tons per year. As a result of the reconstructions carried out, the productivity increased to 450 thousand tons per year. [18].

The main target product of the LG-35-11/300-95 unit is high-octane motor gasolines with an octane rating of up to 95 points (according to the research method). The plant also produces liquefied domestic gas and hydrogen-containing gas (HCG).

Currently, the installation of LG-35-11/300-95 Atyrau Refinery consists of the following blocks: prehydro treating straight run gasoline (naphtha); reforming unit of hydro treated gasoline, i.e. hydrogenate and platform stabilization unit.

The process flow diagram of the catalytic reforming unit with the listed units is shown in fig. 1 .

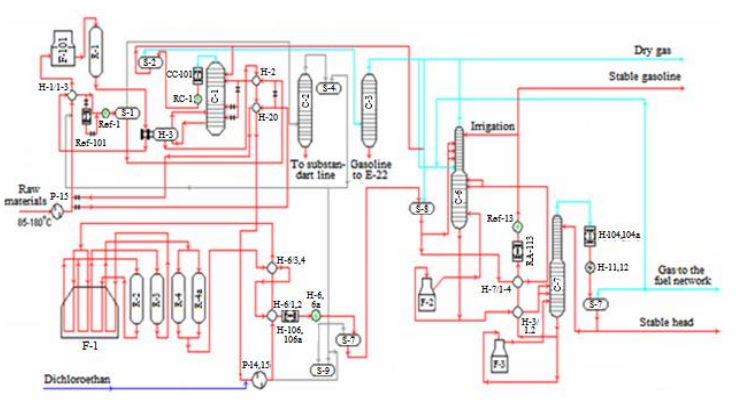

Fig. 1. Process flow diagram of the LG-35-11/300-95 catalytic reforming unit. Technological lines: red - petrol; grey - HCG; Birch - process gas; Blue - Dichloroethane.

Hydrotreating unit. In this block, a hydrotreating process takes place with the participation of technical hydrogen (HCG) and a UOP - S-12T catalyst. The mixture of raw materials and HCG is fed through the P16 pump to the series-connected heat exchangers $\mathrm{H}-1 / 1$ 3. This block dues to the counter flow of carbonated raw materials from the reactor $\mathrm{R}-1$ and reboiler $\mathrm{H}-3$ are heated to a temperature of $260^{\circ} \mathrm{C}$. Then the raw material is fed to the F-101hydrotreating furnace. From the F-101 furnace, a mixture of raw materials and gas with a temperature of $300-343{ }^{\circ} \mathrm{C}$ is fed to the $\mathrm{R}-1$ hydro treating reactor. In the reactor $\mathrm{R}-1$ with the participation of catalyst S-12, the reaction of hydrotreating the feedstock proceeds, i.e. the raw material is preliminarily hydro treated from sulfur, nitrogen and oxygencontaining compounds. The heat of the mixture of unstable hydrogenate, circulating gas from the outlet of the reactor and the heat of reaction of gases with a temperature of $340-420{ }^{\circ} \mathrm{C}$ is used to heat the mixture of raw materials and gas, first in the heat exchanger $\mathrm{H}-3$ of the stripping column $\mathrm{C}-1$, then in the heat exchangers $\mathrm{H}$ $1 / 1-3[18]$.

The products, after cooling to $35^{\circ} \mathrm{C}$ the temperature in refrigerators $\mathrm{XB}-101$ and $\mathrm{X}-1$ is supplied to the separator S-1. HBG is separated from the liquid and for removal of hydrogen is fed to the absorber C-2. Gas from the outlet of the absorber $\mathrm{C}-2$ and after passing through the separator S-4 is divided into two streams:

1) circulating gas, after compression in the compressors is fed back to the feedstock hydro treating system;

2) excess HCG from the outlet of the installation, the liquid phase of the separator $\mathrm{C}-1$ passes through the heat exchanger $\mathrm{H}-2$, here it is heated to a temperature of 150 ${ }^{\circ} \mathrm{C}$ and floats on 7, 9, 23 trays of the stripping column $\mathrm{C}$ 1. In column $\mathrm{C}-1$, hydrogenated product with a temperature of up to $270{ }^{\circ} \mathrm{C}$ and a pressure of up to 15 
atm is stripped of sulfuric hydrogen and water, in addition, light hydrocarbons are removed from the top of the column.

After the stripping column $\mathrm{C}$-1, the total composition of sulfur compounds in the hydrogenation product should not exceed $0.0005 \%$ mass. Gases in the state of vapor from the top of the column $\mathrm{C}-1$ come out with a temperature of $135{ }^{\circ} \mathrm{C}$, pass through the coolingcondensers Ref-101 and Ref-1 and with a temperature of $35-40{ }^{\circ} \mathrm{C}$ are fed to the separator S-2. From the separator $\mathrm{S}-2$, the liquid phase is returned to the stripping column $\mathrm{C}-1$. Hydrocarbon gas from the S-2 separator enters the C-3 absorber for purification from hydrogen sulfide. Hydrocarbon gas from the top of the C-3 absorber is supplied to the fractionating absorber of another block or to the fuel network of the plant.

Thus, in the process of hydrotreating, a chemical transformation of a substance occurs under the influence of hydrogen gas with high pressure and high temperature $[4,19]$. The hydrotreating process consisting of petroleum fuels reduced sulfur compounds, saturate additional unsaturated hydrocarbons, reduction of the resin composition, the oxygenate compounds and hydrocracking of hydrocarbon molecules.

The reforming unit is designed for the conversion of naphthenes and paraffins into aromatic hydrocarbons using the UOP-R-56 catalyst. Aromatic hydrocarbons, thanks to their high octane numbers, are used as commercial quality gasoline.

In the catalytic reforming unit, the hydrogenate, i.e. the product of the hydro treating unit, through heat exchangers $\mathrm{H}-2$ and $\mathrm{H}-20$, enters the intake of pumps $\mathrm{P}-$ 14,15 and is mixed under pressure with the circulating gas. Then the resulting mixture will be heated by the heat of the reforming reactors $\mathrm{R}-2, \mathrm{R}-3, \mathrm{R}-4, \mathrm{R}-4 \mathrm{a}$ is heated in H-6. Then it enters the R-1 furnace for heating to the required temperature. To increase the activity of the catalyst, dichloromethane is injected onto the heated stream (before R-2, R-3, R-4, R-4a).

In reactors $\mathrm{R}-2, \mathrm{R}-3, \mathrm{R}-4, \mathrm{R}-4 \mathrm{a}$ extends reforming process. At the same time, the intermediate heating of these reactors is carried out by the F-1 multi-chamber reforming furnace. Since the aromatization process has a negative thermal effect, the temperature in R-2, R-3, R4 , R-4a decreases. The decrease of temperature is restored to $490-530{ }^{\circ} \mathrm{C}$ due to heating in the second and third stages of the reforming furnace.

From the parallel-connected reactors R-4 and R-4a, the product mixture, which has a temperature of 490-530 ${ }^{\circ} \mathrm{C}$, enters the heat exchangers $\mathrm{H}-6 / 3-4$. Cooling in these heat exchangers to a temperature of $250-300{ }^{\circ} \mathrm{C}$, the gasproduct mixture is fed to the $\mathrm{S}-7$ separator, in which it is separated into target products, i.e. for liquid catalysis and HCG. The obtained unstable catalysis from the highpressure separator S-7 is fed to the separator S-8 (lowpressure separator) for further separation. The separated hydrocarbon gas together with the gases of the K-3 absorber is fed into the column C-6 (fractionating absorber). Heating up to $156^{\circ} \mathrm{C}$ in $\mathrm{H}-7$, the rest of the catalysis for fractionation is fed down the column C-6. Hydrogen-containing gas from the top of the S-7 separator through the S-9 separator (circulating gas separator) is fed back to the reforming system.

Since the unit under study is characterized by a deficit of quantitative information and the vagueness of some important parameters that affect the efficiency of the facility and the quality of products, problems. These factors arise in the development of mathematical models and control of the processes of improving the quality of gasoline, using traditional mathematical methods. But at this facility, experienced process operators have been working for many years, who are decision makers, expert specialists and can effectively manage the hydrotreating process based on their intuitions, knowledge and experience, i.e. using fuzzy information.

Thus, the object under study functions under conditions of uncertainty due to the deficit and indistinctness of the initial information. Therefore, it will be necessary to solve the problems of developing a system of mathematical models of interconnected technological objects of the catalytic reforming unit using the initial fuzzy information in the form of knowledge, experience and intuitions of decision makers and experts. The resulting system (package) of models) with the help of decision-making methods allows you to select the optimal operating modes of the technological unit in a fuzzy environment, providing a significant economic effect [20, 21]. Therefore, in order to optimize and effectively control a catalytic reforming process unit, it is necessary to develop a system of adequate mathematical models of interconnected units of these units using available information of a different nature, incl. fuzzy information. For this, experimental statistical methods are used in the methods [22, 23], methods of system analysis [24, 25], methods of expert assessments and the mathematical apparatus of theories of fuzzy sets as well as hybrid methods for the development of mathematical models [7 - 10, 26]. Informal methods of systems analysis and expert methods during research allow you to collect, process and use formalized fuzzy information to build mathematical models.

Research in this work is carried out in the following sequence:

- study and description of the object - the investigated technological unit; collection processing of available experimental and statistical information on the functioning of the object;

- organizing and conducting an expert assessment to collect the missing part of the initial information about the operation of the object in the form of fuzzy information;

- processing of collected fuzzy information, definition of term-sets and construction of a function of accessories of fuzzy parameters of the research object;

- creation of a methodology for constructing a package of mathematical models of interconnected objects of a technological unit based on available information of an experimental-statistical, fuzzy nature and theoretical information about the object; 
- on the basis of the proposed methodology, the development of a package of mathematical models of the technological unit;

- using the developed models and methods of decision-making in a fuzzy environment, select the optimal operating mode of the technological unit for the production of high-quality gasoline, which ensures high efficiency and environmental safety of the research object.

\section{Results and discussions}

A catalytic reforming unit LG-35-11/300-95 is a complex CTS, consisting of interconnected blocks and units, which are simultaneously affected by a large number of different parameters. The main interconnected units of the installation include: a reactor (hydrotreater R-1; reforming R-2, R-3, R-4, R-4a), columns (C-1, C-2, $\mathrm{C}-3)$; hydrotreating and reforming furnaces F-101, F-1; separators, heat exchangers, etc. (see fig. 1). For system modeling of the catalytic reforming unit operation, it is necessary to develop a package of mathematical models of these main units. Since the technological units of the catalytic reforming unit are interconnected, changes in the operating parameters of one of them lead to changes in the parameters of the others, which affect the processes of hydrotreating and reforming. In this regard, in order to optimize and control the process of hydrotreating and reforming in the optimal mode, it is necessary to have a package of related mathematical models of these main units, which are compiled on the basis of a systematic approach [24].

In practice, under production conditions, some important parameters characterizing the quality of products of hydrotreating and reforming processes are difficult to measure quantitatively or not measured, but can be imprecisely assessed by decision makers and experts. In practice, due to the experience, knowledge and intuition of the operator-technologist, decision maker, formalized in the form of fuzzy information, the problem of choosing effective operating modes and managing these objects is often successfully solved. Therefore, based on the methodology of system analysis, we propose a methodology for determining the optimal types and developing a package of models of interconnected aggregates of complex chemical engineering systems in a fuzzy environment, which includes a catalytic reforming unit.

Methodology for the development of models of interconnected units for systemic modeling of CTS on the example of a catalytic reforming process unit. As a result of the analysis of various methods for the development of mathematical models of complex chemical engineering systems. It was revealed that in research works, the issues of systemic modeling of a technological system, consisting of interconnected technological units in the absence of quantitative information, are poorly covered. In conditions of uncertainty associated with a lack of initial information, it is usually proposed to apply probabilistic modeling methods or simulation methods [22, 27, 28]. However, in cases of uncertainty due to the lack of clarity of the initial information, which often occurs in real production conditions, the use of probabilistic methods is unjustified. This is due to the fact that, under these conditions, statistical information is insufficient or absent, and the axioms of probability theory (statistical stability of an object, repeatability of experiments under the same conditions, etc.) are not fulfilled. Sometimes the available initial information is only fuzzy information, which is the knowledge, experience and judgments of decision makers and experts. With the competence of these sources of information and with the correct organization of their interrogation, collection and processing of fuzzy assessment show, for complex units of the LG-35-11/300-95 plant such as reactors, furnaces, due to the difficulty of studying the processes occurring in them and the impossibility of obtaining reliable data, the construction of deterministic models information on its basis, it is possible to build models that take into account all the complex relationships of various parameters and variables of the object under study. The resulting models based on fuzzy information can be more meaningful than models developed by traditional methods, and most importantly, adequately describe real production facilities and tasks.

We assume to consider the main idea of the proposed methodology for the development of a package of mathematical models of interconnected CTS units using the example of the development of a package of models for the main technological units of a catalytic reforming unit.

Mathematical models of each unit (element) of CTS can be constructed using various methods, depending on the availability and availability of one or another type of initial information and on other factors. Thus, for individual elements of the chemical engineering system, it is possible to build various types of models, for example, statistical, fuzzy or combined. Therefore, to combine such models into a single package (system) of models, on the basis of which system modeling and optimization of the installation as a whole are carried out, it is necessary:

- to analyze the advantages and disadvantages of each type of model, the construction of which is possible;

- to develop criteria for comparison and selection of models by cost, by purpose, by accuracy, etc.;

- to determine the principles of combining the developed models into a single package.

Based on the results of the study, an analysis of various types of models of the main units of the LG-35$11 / 300-95$ catalytic reforming unit was carried out. As a result of studies of the specifics of the main units of the catalytic reforming unit $[12,18,29]$, experimental data and expert demand, and analysis of approaches to modeling such or similar units, an assessment of possible types of models of the main units of the catalytic reforming unit was carried out. The result of the system analysis carried out on the assessment of models is presented in the form of table 1. For assessment, i.e. ranking of model types used a five-point scale. 
As the main criteria for comparing and choosing the optimal type of model, by which they are evaluated, the following are highlighted: the availability of the necessary information for building a model of the corresponding type; the cost of developing a model; the degree of model adequacy; the applicability of the model for solving the problem of optimization and control in a fuzzy environment; the possibility of combining the developed model into a single package for the purpose of systemic modeling of the block as a whole.

Table 1 presents the results of the expert evaluation according to the given criteria for comparison and choice of the type of model of the main units of the catalytic reforming unit. These results are obtained on the basis of processing the results of the expert analysis by the Delphi method [7]. Based on the information given in the above table, it is possible to make a multicriteria choice of the optimal type of the model of the catalytic reforming unit units according to the specified comparison criteria and the choice of the model type. The optimal model type is determined by the maximum value of the integrated criterion. Since the local criterion does not have a unit of measurement (points), the integrated criterion for choosing the optimal type of model is defined as the sum of local criteria.

Here are the main points of discussion of the results. As the results of the analysis and for them is practically impossible or economically inexpedient. For heat exchangers, the construction of deterministic models is possible, since there is sufficient theoretical information necessary to build a model of this type and the integrated criterion takes the maximum value (23) (see table 1).
Table 1. Analysis and assessment of the types of models of the main units of the reforming unit LG-35-11/300-95.

\begin{tabular}{|c|c|c|c|c|c|}
\hline \multirow[b]{2}{*}{$\begin{array}{l}\text { Aggregat } \\
\text { es } \\
\text { catalytic } \\
\text { reforming } \\
\text { units } \\
\text { (main) }\end{array}$} & \multirow[b]{2}{*}{$\begin{array}{l}\text { Criterion for comparison } \\
\text { and choice of model type }\end{array}$} & \multicolumn{4}{|c|}{ Types of models } \\
\hline & & 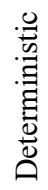 & . & 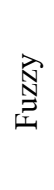 & 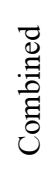 \\
\hline \multirow{6}{*}{$\begin{array}{l}\text { Reactors: } \\
\text { R-1; R-2; } \\
\text { R-3; } \\
\text { R-4, R-4a }\end{array}$} & $\begin{array}{l}\text { Availability of necessary } \\
\text { information }\end{array}$ & 2 & 4 & 4 & 5 \\
\hline & Development cost & 1 & 4 & 3 & 3 \\
\hline & Degree of adequacy & 4 & 3 & 4 & 4 \\
\hline & $\begin{array}{l}\text { Applicability for solving } \\
\text { the problem of optimiza- } \\
\text { tion and control }\end{array}$ & 3 & 3 & 4 & 5 \\
\hline & $\begin{array}{l}\text { Possibility of combining } \\
\text { the model into a package }\end{array}$ & 4 & 3 & 3 & 3 \\
\hline & Integrated criterion & 14 & 17 & 18 & 20 \\
\hline \multirow{5}{*}{$\begin{array}{l}\text { Furnaces: } \\
\text { F-101, } \\
\text { F-1 }\end{array}$} & $\begin{array}{c}\text { Availability of necessary } \\
\text { information }\end{array}$ & 3 & 5 & 4 & 5 \\
\hline & Development cost & 2 & 4 & 4 & 4 \\
\hline & Degree of adequacy & 5 & 4 & 4 & 4 \\
\hline & $\begin{array}{l}\text { Applicability for solving } \\
\text { the problem of optimiza- } \\
\text { tion and control }\end{array}$ & 4 & 5 & 4 & 4 \\
\hline & $\begin{array}{l}\text { Possibility of combining } \\
\text { the model into a package }\end{array}$ & 4 & 4 & 4 & 4 \\
\hline & Integrated criterion & 18 & 22 & 20 & 21 \\
\hline \multirow{6}{*}{$\begin{array}{l}\text { Separa- } \\
\text { tors: } \\
\text { S-1; S-2; } \\
\text { S-7; } \\
\text { S-8; S-9 }\end{array}$} & $\begin{array}{c}\text { Availability of necessary } \\
\text { information }\end{array}$ & 4 & 5 & 4 & 5 \\
\hline & Development cost & 3 & 4 & 4 & 4 \\
\hline & Degree of adequacy & 5 & 4 & 4 & 4 \\
\hline & $\begin{array}{l}\text { Applicability for solving } \\
\text { the problem of optimiza- } \\
\text { tion and control }\end{array}$ & 4 & 5 & 4 & 4 \\
\hline & $\begin{array}{l}\text { Possibility of combining } \\
\text { the model into a package }\end{array}$ & 4 & 4 & 4 & 4 \\
\hline & Integrated criterion & 20 & 22 & 20 & 21 \\
\hline \multirow{6}{*}{$\begin{array}{c}\text { Heat exc- } \\
\text { hangers: } \\
\text { H-1; H-2; } \\
\text { H-3; H-6, } \\
\text { refrige- } \\
\text { rators: } \\
\text { Ref-1; } \\
\text { Ref-6 }\end{array}$} & $\begin{array}{l}\text { Availability of necessary } \\
\text { information }\end{array}$ & 5 & 4 & 4 & 5 \\
\hline & Development cost & 5 & 3 & 4 & 3 \\
\hline & Degree of adequacy & 5 & 5 & 4 & 5 \\
\hline & $\begin{array}{l}\text { Applicability for solving } \\
\text { the problem of optimiza- } \\
\text { tion and control }\end{array}$ & 4 & 5 & 5 & 5 \\
\hline & $\begin{array}{l}\text { Possibility of combining } \\
\text { the model into a package }\end{array}$ & 4 & 5 & 4 & 4 \\
\hline & Integrated criterion & 23 & 22 & 21 & 22 \\
\hline
\end{tabular}

Authors should use the forms shown in Table 1 in the final reference list.

Statistical (stochastic) models of F-101 and F-1 furnaces and S-1 separators; S-2; S-7; S-8; S-9 catalytic reforming units are relatively easy to build, convenient for combining them into a single system of models and are suitable for solving problems of optimization and plant control. According to the results of the study, it can be concluded that for furnaces and separators, the most optimal is the development of statistical models since the integrated criterion takes the maximum value -22 points each.

At the catalytic reforming unit LG-35-11/300-95 of the Atyrau Refinery, the collection of reliable experimental and statistical information for the 
construction of statistical mathematical models of the R1 hydrotreating reactors and the R-2, R-3, R-4, R-4a reforming reactors is hampered by the lack of special industrial instruments and low reliability of the available measuring instruments. This is confirmed by the results of the expert assessment, since the integrated criterion for these types of model is low.

In this regard, as a more effective mathematical apparatus that supplements the missing data on the basis of fuzzy information, the methods of fuzzy set theories have been chosen $[9,10]$. At the same time, to collect fuzzy information - expert opinions in natural language, methods of expert assessments are used, for example, the Delphi method. For the formalization, processing and use of fuzzy information in the construction of models, methods of fuzzy set theories and combined (hybrid) methods of developing models are used [9, 10, 11, 20, $26,27]$. As can be seen from Table 1, the optimal type of model for reactors is combined models, which are built using available information of a different nature, for example, statistical data and fuzzy information. The adequacy of such hybrid models, with the correct and full use of available data and fuzzy information is high enough, and they can also be effectively used to optimize reforming processes.

Thus, in practice, to build models with a shortage of initial information, one has to use any available information. Models of technological units obtained on the basis of such data will be called combined. They can be obtained using various combinations of available data. However, the construction of combined models may be impractical due to the fact that a stage of organization, research and experiments of a different nature is required, as well as preliminary processing of the collected data.

The combination of individual models of units into a package is carried out in accordance with the course of the technological process in the chemical engineering system. In this case, the outputs of one model, i.e. the simulation results of one unit are input parameters for the model of another unit. For example, in the catalytic reforming unit, the simulation results of the R-2 reactor are the initial data for modeling the operation of the 2 nd stage of the F-1 multi-chamber furnace; the simulation results of this furnace stage are the input data for the R-3 reactor models. And the results of modeling the operation of the R-3 reactor are the initial data for the third stage of the P-1 furnace, the output results, which are the initial data for the models of the R-4, R-4a reactors. Thus, in addition to the adequacy and effectiveness of their use in the computer system for modeling and optimizing the operating modes of the installation, the main criteria for choosing the types of models of units, i.e. mutual correspondence of the output and input variables of the related models.

Based on the results of research and analysis of the operation of interconnected units of hydrotreating and reforming units of the catalytic reforming unit and in accordance with the flow of hydrotreating and reforming processes, the developed models are combined into a single package of models. The scheme of combining individual models of the main units into a package of models is shown in fig. 2 .

In the above diagram of combining individual models of units into a single package of models (fig. 2) through F-101, F-1,H-3, S-1, S-2, C-1, C-2, C-3, R-1, R2, R-3, R-4, R-4a, H-6, S-7, software models of the main units of the hydrotreating and reforming units of the LG35-11/300-95 unit are indicated. For convenience, the designations of the programs are taken in accordance with the designations of the modeled main units of the catalytic reforming unit discussed above. With the help of this software package on a computer, it is possible to systematically simulate various operating modes of the catalytic mode installation and determine the optimal operating modes that provide a significant economic effect and environmental safety of production. In addition, system modeling of the operation of a technological unit allows identifying the "bottlenecks" of the plant, the solution of which will allow increasing the power and productivity of the technological unit.

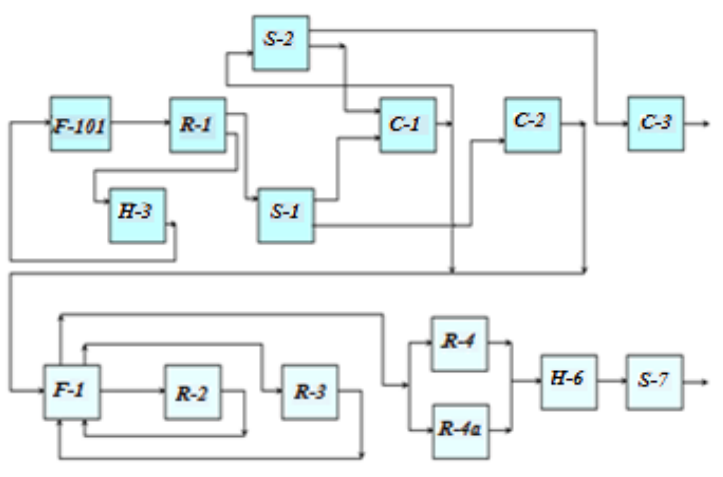

Fig. 2. Scheme of combining models of the main units of hydrotreating and reforming units of the LG-35-11/300-95 catalytic reforming unit of the Atyrau Refinery into a package of models.

On the basis of the system analysis methodology, we propose a methodology for the development of mathematical models of interconnected units of cold storage systems. For example, the LG-35-11/300-95 installation based on fuzzy information and other available data. In this case, the available initial information can be statistical, experimental data, theoretical information and a fuzzy description of the object's operation..

The proposed methodology for the development of models of interconnected CTS units consists of the following main points:

1. Investigation of CTS by methods of system analysis, collection and processing of available information about the state and operation of system elements and their interconnections, determination of the purpose of modeling;

2. Taking into account the purpose of modeling, generate criteria for comparing and evaluating the types of models of CTS elements that can be constructed for the element;

3. Organize and conduct an expert assessment of each type of model for the cold-weather units according to the selected criterion and, using the integrated 
criterion, determine the effective type of model for each unit.

4. Taking into account the results of system analysis and expert assessment, and depending on the characteristics of the available initial information, build various types of models. To determine the optimal type of model and build the corresponding model, go to the subsequent paragraphs.

5 If there is sufficient theoretical information describing the operation of the investigated element of the CTS and, according to the integrated criterion, the deterministic models has a maximum value, then for it, using analytical methods, build a deterministic model. Otherwise go to the next step.

6. If the statistical data that describe the operation of the investigated element (unit) of the CTS are sufficient, or they can be collected on the basis of experiments, according to the integrated criterion, the statistical model is optimal, i.e. takes the maximum value, then on the basis of experimental and statistical methods to construct a statistical model of the unit. Otherwise go to the next step.

7. If both theoretical and statistical information describing the operation of the investigated unit is insufficient, and the collection of such information is impossible or economically inexpedient, but there is unclear information about the object, then the following sittings are possible. In the case of the maximum value of the integrated criterion of the fuzzy model, if the input parameters of the unit are clear, and the output parameters are fuzzy, then go to step 9 to build the fuzzy model. Otherwise, i.e. in the case of unclearness of both the input and output parameters of the unit, to build a linguistic model, go to the next step.

8. Identify and select informative input $\tilde{x}_{i} \in \widetilde{A}_{i}, i=\overline{1, n}$ and output $\tilde{y}_{j} \in \widetilde{B}_{j}, j=\overline{1, m}$ fuzzy parameters (variables) of the unit, describing, respectively, input, operating parameters, and the quality of the unit. These parameters are necessary for building the model and are linguistic variables: $\widetilde{A}_{i} \in X, \widetilde{B}_{j} \in Y-$ fuzzy subsets, $X, Y-$ universal sets, input and output parameters.

8.1. Based on the methods of expert evaluation with the involvement of decision makers, determine term sets $T\left(\tilde{X}_{i}, \tilde{Y}_{j}\right)$, describing the parameters of the simulated object and construct membership functions of the fuzzy parameters of the object: $\mu_{A_{i}}\left(\tilde{x}_{i}\right), \mu_{B_{j}}\left(\tilde{y}_{j}\right)$.

Based on the experience of modeling technological objects of oil refining production in a fuzzy environment, we can recommend the following adaptable structure of the membership function:

$$
\mu_{B_{j}}^{p}\left(\tilde{y}_{j}\right)=\exp \left(Q_{B_{j}}^{p}\left|\left(y_{j}-y_{m d j}\right)^{N_{B_{j}}^{p}}\right|\right),
$$

where $\mu_{B_{j}}^{p}\left(\widetilde{y}_{j}\right)$ - membership function describing output fuzzy parameters to a fuzzy set of $\widetilde{B}_{j} ; p$ - quantum number (sampling interval); $Q_{B_{j}}^{p}$-parameter (coefficient) that determines the level of fuzziness, which is determined when identifying the membership function; $N_{B_{j}}^{p}$-coefficients defining the domain of definition of terms of the membership function of fuzzy parameters and allowing to change the shape of the membership function graph; $y_{m d j}^{p}-$ fuzzy variable that most closely matches a given term on a quantum $p$. This variable is determined from the following condition $\mu_{B_{j}}\left(y_{m d j}^{p}\right)=\max _{j} \mu_{B_{j}}\left(y_{j}\right) \cdot$

8.2 Determine connections between input and output linguistic variables, i.e. build fuzzy mappings $R_{i j}$ between $\tilde{x}_{i}$ and $\tilde{y}_{j}$. For the convenience of using fuzzy mapping in the calculation, the matrix of connections with membership functions is determined:

$$
\mu_{R_{i j}}\left(\tilde{x}_{i}, \tilde{y}_{j}\right)=\min \left(\mu_{A_{i}}\left(\tilde{x}_{i}\right), \mu_{B_{j}}\left(\tilde{y}_{j}\right)\right), i=\overline{1, n}, j=\overline{1, m} .
$$

Then linguistic model is built having the general structure:

$$
\operatorname{IF} \tilde{x}_{1} \in \tilde{A}_{1}\left(\tilde{x}_{2} \in \tilde{A}_{2}\left(, \ldots,\left(\tilde{x}_{n} \in \tilde{A}_{n}\right), \ldots,\right), \text { THEN } \tilde{y}_{j}^{M} \in \tilde{B}_{j}, j=\overline{1, m}\right.
$$

8.3 Based on the composite output rules $\widetilde{B}_{j}=\widetilde{A}_{i} \circ R_{i j}$ to determine the fuzzy values of the output parameters of the investigated element of the CTS, then from the fuzzy solutions the numerical values of the output parameters are determined In this case, using the compositional inference rule, the output parameters of the object are determined, which determine the quality of its work, for example, using the maximin product.Let be $\tilde{x}_{i}^{*}$ - means the values of the input fuzzy parameters of the object, assessed by experts. In this case, the set of current values of the input parameters is defined as a fuzzy set in which the membership functions of the input parameters will be maximal: $\mu_{A_{i}}(\tilde{x})=\max \left(\mu_{A_{i}}\left(\tilde{x}_{i}^{*}\right)\right)$. Then the fuzzy values of the output variables are determined in the form of membership functions, expressing the maximum product:

$$
\mu_{B_{j}}\left(\tilde{y}_{j}^{*}\right)=\max \left\{\min _{x_{i} \in X}\left(\mu_{A_{i}}\left(\tilde{x}_{i}^{*}\right), \mu_{R_{i j}}\left(x_{i}^{*}, \tilde{y}_{j}\right)\right)\right\}
$$

The quantitative values of the output parameters can be determined using the following expression: $y_{j}^{c}=\arg \max _{\tilde{y}_{j}^{*}} \mu_{B_{j}}\left(\tilde{y}_{j}^{*}\right)$, i.e., selects the values of the output parameters in which the membership function reaches its maximum values. In order to verify and ensure the adequacy of the models go to step 11 .

9. Identify and select clear input $x_{i} \in A_{i}, i=\overline{1, n}$ and output fuzzy $\tilde{y}_{j} \in \widetilde{B}_{j}, j=\overline{1, m}$ unit parameters, describing, respectively, input, operating parameters, and the quality of the unit. These parameters are necessary for constructing a fuzzy model of the investigated CTS unit. 
9.1 Determine the structure of fuzzy models $\tilde{y}_{j}=\tilde{f}_{j}\left(x_{1}, \ldots, x_{n}, \tilde{a}_{0}, \tilde{a}_{1}, \ldots, \tilde{a}_{n}\right), \quad j=\overline{1, m} \quad$ (structural identification of models). For example, the structure of the model can be defined in the form of multiple regression fuzzy equations:

$$
\tilde{y}_{j}=\tilde{a}_{0 j}+\sum_{i=1}^{n} a_{i j} x_{i j}+\sum_{i=1}^{n} \sum_{k=i}^{n} a_{i k j} x_{i j} x_{k j,} j=\overline{1, m} .
$$

9.2 Solve the problem of parametric identification of fuzzy parameters, i.e. regression coefficients $\left(\tilde{a}_{0}, \tilde{a}_{1}, \ldots, \tilde{a}_{n}\right)$, for example, using the method of least squares modified on the basis of the set of level $\alpha$, and go to step 11 .

10. If both theoretical and statistical data and fuzzy information describing the operation of a technological system unit are insufficient or their collection is not economically feasible. The integrated criterion according to the combined model has the maximum estimate using the hybrid method, build a combined (hybrid) model [26]. In this case, the combined model is developed on the basis of available information of a different nature (theoretical, statistical, fuzzy). To do this, to describe a specific parameter of the object, various combinations of the above described points of the methodology 6, 8, 9 are used.

11.Checking the adequacy of the model by condition: $R=\min \sum_{j=1}^{m}\left(y_{j}^{M}-y_{j}^{E}\right)^{2} \leq R_{D}$, where $y_{j}^{M}-$ calculated (model), a $y_{j}^{E}$ - experimental (real) values of the object's output parameters, $R_{D}$ - allowable deviation value. If the adequacy of the condition is satisfied, then the model is recommended for modeling and determining the optimal operation modes of the object. Providing an increase in the efficiency of the object, in our case, a catalytic reforming unit. Otherwise, the reason for the inadequacy of the model is determined and the transition is processed to the corresponding points of the described methodology to eliminate the causes of inadequacy and increase it. In this case, the reason for the inadequacy of the model can be: not including some parameters in the model that significantly affect the process; incorrect structural and / or parametric identification of the model, etc..

Discussion. As can be seen from paragraphs 5 - 9 of the above methodology for the development of models of interconnected units of the CTS, the models of each unit can be built using different initial information and appropriate methods for developing models. As a result, various types of models can be built, for example, statistical, fuzzy, or combined. Then these models are combined into a single package of models in accordance with the process flow scheme, i.e. modeling results of one aggregates are taken as input data for models of other aggregates. The scheme of combining the models of the investigated catalytic reforming unit LG-3511/300-95 of the Atyrau Refinery is shown in fig. 2.

As a result of the application of the above proposed methodology for the development of models of interconnected CTS units, models of the main units of the catalytic reforming unit were built. For example, volume estimation models $\left(y_{1}^{R_{4,4 a}}\right)$ and quality $\left(\tilde{y}_{2}\right.$ octane number) products-catalyzate reforming unit were obtained in the form of the following combined model:

$$
\begin{aligned}
& y_{1}^{R_{4,4 a}}=0.3989835 \cdot x_{1}+11.1869231 \cdot x_{2}-0.031589537 \cdot x-{ }_{3} \\
& -1.02391304 \cdot x_{4}+0.0253700 \cdot x_{5}+0.005069676 \cdot x_{1}^{2}+ \\
& +9.289940828 \cdot x_{2}^{2}-0.000058560 \cdot x_{3}^{2}-0.044517958 \cdot x_{4}^{2}+ \\
& +0.000049063 \cdot x_{5}^{2}++0.230182778 \cdot x_{1} x_{2}+0.000100348 \cdot x_{1} x_{3}+ \\
& +0.002168388 \cdot x_{1} x_{4}+0.000498729 \cdot x_{1} x_{5}+0.036449466 \cdot x_{2} x_{3}- \\
& -0.525083612 \cdot x_{2} x_{4}-0.000686729 \cdot x_{3} x_{4} \\
& \tilde{y}_{2}=0.436 \cdot x_{1}-20.0769 \cdot x_{2}+0.0583 \cdot x_{3}-0.7220 \cdot x_{4}+ \\
& +0.0424 \cdot x_{5}+0.0054 \cdot x_{1}^{2}-15.4460 \cdot x_{2}^{2}+0.0001 \cdot x_{3}^{2}- \\
& -0.0302 \cdot x_{4}^{2}+0.0001 \cdot x_{5}^{2}+0.00022 \cdot x_{1} x_{3}+0.00033 \cdot x_{1} x_{5}- \\
& -0.05577 \cdot x_{2} x_{4}+0,00095 \cdot x_{3} x_{5}-0.0302 \cdot x_{4}^{2}+0.0001 \cdot x_{5}^{2}+ \\
& +0.00022 \cdot x_{1} x_{3}+0.00033 \cdot x_{1} x_{5}-0.05577 \cdot x_{2} x_{4}+0,00095 \cdot x_{3} x_{5}
\end{aligned}
$$

where $x_{i}, i=\overline{1,5}$ - input, operating parameters of reforming reactors: $x_{1}$ - consumption of supplied raw materials; $x_{2}-$ space velocity in reforming reactors; $x_{3}$ - the temperature in the reforming reactor; $x_{4}$ - the pressure in the reforming reactor; $x_{5}$ - hydrogen / feed ratio.

For shorthand, the fuzzy model estimating the octane number $\tilde{y}_{2}$ is given after combining the fuzzy

\begin{tabular}{|c|c|c|c|}
\hline $\begin{array}{l}\text { Output parameters } \\
\text { evaluating the quantity } \\
\text { and quality of products }\end{array}$ & $\begin{array}{l}\text { Known, } \\
\text { determinis } \\
\text { ticmodels }\end{array}$ & $\begin{array}{c}\text { Develope } \\
\mathrm{d} \text { models } \\
\text { with fuzzy } \\
\text { informa- } \\
\text { tion }\end{array}$ & $\begin{array}{l}\text { Real } \\
\text { data }\end{array}$ \\
\hline $\begin{array}{c}\text { Output targetproduct, \% } \\
\text { (mass) }\end{array}$ & 94,7 & 95.3 & 95.0 \\
\hline $\begin{array}{l}\text { The content of aromatic } \\
\text { hydrocarbons } y_{A}, \% \\
\text { (mass.) }\end{array}$ & 68,9 & - & - \\
\hline $\begin{array}{c}\text { Output catalyst } \\
\text { (volume) } \mathrm{m}^{3} / \text { hour }\end{array}$ & 77,2 & 77,9 & 77.7 \\
\hline $\begin{array}{l}\text { The octane number of } \\
\text { catalyzate by the motor } \\
\text { method }\end{array}$ & & 87 & $(86)^{\mathrm{L}}$ \\
\hline \multicolumn{4}{|c|}{$\begin{array}{l}\text { Note: the input and operating parameters of the process are } \\
\text { taken approximately the same; }(.)^{\mathrm{L}} \text { means that the data was } \\
\text { determined with human participation by laboratory. }\end{array}$} \\
\hline
\end{tabular}
coefficients using the center of gravity method, i.e. after the defasification procedure.

The results of modeling the operation of reforming reactors and comparing them with the results of modeling other known models of reforming, as well as real data obtained from the LG unit of the Atyrau refinery are shown in table 2 .

Table 2. Results of modeling based on known models [30], developed models taking into account fuzzy information and real data from the LG-35-11 / 300-95 unit of the Atyrau oil refinery factory. 
The discussion of the results. As can be seen from the data shown in table 2, the results of modeling based on the developed models, built taking into account the fuzziness of some of the initial information, are better than the results of modeling using known deterministic models. The advantages of the developed reactor models are that they make it possible to determine a more efficient operating mode of the reactors. The effectiveness of such a regime is that the percentage of the target product yield, the volume of catalysts from the reactors increases and more accurately corresponds to the values of real data. Thus, we can conclude that the developed models are more adequate than the deterministic models. In addition, the developed models make it possible to determine quality indicators, i.e. octane number of catalysts and its fractional composition, which are characterized by fuzziness.

\section{Conclusions}

This work is presented results of a study on improving the efficiency of technological units for the production of high-quality motor fuels on the example of a catalytic reforming unit at the Atyrau Refinery under conditions of shortage and unclear initial information. To solve the problems of uncertainty, probabilistic and statistical methods were used, and when the initial information is unclear, the methods of theories of fuzzy sets. A methodology for the development of models of interconnected units for system modeling in order to increase the efficiency of chemical-technological systems is proposed and described on the example of a catalytic reforming process unit. The results of the system analysis and expert evaluation of the types of models of the main units of the catalytic reforming unit LG-35-11/300-95 and the choice of the optimal type of model for individual units of the unit under study are presented. A diagram of combining models of the main units of hydrotreating and reforming units of the LG-3511/300-95 catalytic reforming unit of the Atyrau Refinery into a single package of models is presented.

The novelty of the proposed methodology for the development of mathematical models of interconnected units of a technological system lies in the application of a systematic approach, the use of fuzzy information and other available data, which provide solutions to the problem of uncertainty. The proposed methodology also makes it possible to develop the most efficient type of models for individual units of the technological system. Also helps to create a package of models and carry out system modeling of the installation in order to determine the optimal modes of its operation and increase efficiency. On the basis of the proposed methodology for the development of models of interconnected units of the technological system, combined models have been built to determine the volume of the produced catalyzate (product) and its quality (octane number) of the reforming unit. The given work is presented comparison of simulation results based on known models, developed models taking into account fuzzy information and real (production) data from the LG-35-11/300-95 unit of the
Atyrau Refinery. The advantages of the developed models are shown taking into account the fuzziness of some of the initial information.

Funding: the Science Committee of the Ministry of Education and Science of the Republic of Kazakhstan (Grant No. fund this research AP08855680-Intelligent decision support system for controlling the operating modes of the catalytic reforming unit).

\section{References}

1. S.A. Akhmetov, Deep processing technology of oil and gas: Study guide for universities (Ufa: Gilem, 672, 2002)

2. S.G. Propopuk, P.H. Masgutov, Industrial catalytic cracking units (M.: Chemestry, 3-edt., 310, 2018)

3. Wang Derek, Li Tianchi, Carbon Emission Performance of Independent Oil and Natural Gas Producers in the United States, Sustainability, 10 (1), 1-18 (2018)

4. Z. Adzamic, S. Besic, The impact of the catalytic reforming operation severity on cycle duration and product quality at the Rijeka oil refinery, Fuels and lubricants, 42 (1), 83-87 (2013)

5. D.D. Khatnullina, Catalytic reforming [Electronic resource], Engineering Science: Theory and Practice: Chita: Young scientist, 106-109 (2014) Available at: https: //moluch.ru/conf/tech/archive/88/4681/

6. P.A. Aliyev, A.E. Tserkovniy, G.A. Mamedova, Production management with fuzzy initial information (M.: Energoatomizdat, 307, 1991)

7. S. Gupykova, Method of expert estimates, Theory and practice (M.: Kogito-center, 509, 2017)

8. H.Z. Sabzi, Developing an intelligent expert system for streamflow prediction, integrated in a dynamic decision support system for managing multiple reservoirs: a case study, Expert system with applications, 82, 3, 145-163 (2017)

9. A.R. Ryzhov, Fuzzy set theory and its applications (M.: MGU, 115, 2017)

10. D. Dubois, The role of fuzzy sets indecision sciences: old techniques and new directions, Fuzzy Sets and Systems, 184, 3-17 (2011)

11. B. Orazbayev, D. Kozhakhmetova, R. Wójtowicz, J. Krawczyk, Modeling of a Catalytic Cracking in the Gasolin Production Installation with a Fuzzy Environment, Energies, 13, 4736, 1-13 (2020) DOI: $10.3390 /$ en 13184736

12. Yu.V. Sharikov, P.A. Petrov, Universal model for catalytic reforming, Chem. And Petroleum Engineering, 43 (9), 580-597 (2013)

13. Shanshan Guo, Fan Zhang, Chenglong Zhang, Chunjiang An, Sufen Wang, Ping Guo, A MultiObjective Hierarchical Model for Irrigation Scheduling in the Complex Canal System, Sustainability, 11 (1), 24 (2019) 
14. G.M. Ostrovsky, N.N. Ziyatdinov, T.V. Lapteva, A. Silvestrova, Optimization of Chemical Process Design with Chance Constraints by an Iterative Partitioning Approach, Journal of Industrial and Engineering Chemistry, 54 (13), 3412-3437 (2015)

15. D. Ibrahim, M. Jobson, J. Li, G. GuillenGosalbez, Optimization-based design of crude oil distillation units using surrogate column models and a support vector machine, Chemical engineering research \& design, 134, 212-225 (2018)

16. Y. Chen, L. He, J. Li, S. Zhang, Multi-criteria design of shale-gas-water supply chains and production systems towards optimal life cycle economics and greenhouse gas emissions under uncertainty, Computers \& chemical engineering, 109, 216-235 (2018)

17. V.G. Matveykin, B.S. Dmitrievsky, A.G. Kokuev, A.M. Dzhambekov, Problem of Control of Catalytic Reforming and Method of its Solutions, Bulletin of the Tomsk Polytechnic University, Geo Assets Engineering, 330 (6), 59-67 (2019) DOI: $10.18799 / 24131830 / 2019 / 6 / 2127$

18. Technological regulations for the catalytic reforming unit LG-35-11 / 300-95, Atyrau, 135 (2018)

19. B.B. Petrov, A.B. Moiseev, E.S. Burdakova, Hydrotreating of straight-run fuels on spherical aluminum-nickel-molybdenum catalysts, Oil Refining and Petrochemicals, 2, 16-19 (2016)

20. B.B. Orazbayev, Ye.A. Ospanov, K.N. Orazbayeva, B.A. Serimbetov, Multicriteria optimizationin control of a chemical technological system for production of benzene with fuzzy information, Bull. of the Tomsk Polytechnic Univ. Geo Assets Eng., 330 (7), 182194 (2019)

21. L.T. Biegler, Y.D. Lang, W.J. Lin, Multi-scale Optimization for Process Systems Engineering, Computers and Chemical Engineering, 10, 17-35 (2016)

22. Zhao Zhi-Wen, Wang De-Hui, Statistical inference for generalized random coefficient autoregressive model, Mathematical and Computer Modelling, 56, 152-166 (2012)

23. B.B. Moizec, Y.B. Plotnikova, L.A. Redko, Statistical quality control methods and experimental data processing (M.: Urait, 2-edt., 118, 2019)

24. S.Yu. Pavlov, N.N. Kulov, R.M. Kerimov, Improvement of Chemical Engineering Processes Using Systems Analysis, Theoretical Foundations of Chemical Engineering, 53 (2), 117-133 (2016)

25. A.B. Andreichikov, Systems analysis and synthesis of strategic decisions in innovation: Mathematical, heuristic and intellectual methods of systems analysis and synthesis (M.: Lenand, 306,2018 )
26. B.B. Orazbayev, E.A. Ospanov, K.N. Orazbayeva, L.T. Kurmangazieva, A Hybrid Method for the Development of Mathematical Models of a Chemical Engineering System in Ambiguous Condition, Mathematical Models and Computer Simulations, 10 (6), 748-758 (2018) DOI: 10.1134/ S2070048219010125

27. B.E. Gmurman, Theory of probability and mathematical statistics: Textbook for universities (M.: Higher education, 479, 2017)

28. U.I. Ryzhikov, Simulation modeling, Author's imitation of systems and networks with queues (SP.: Lan, 112, 2019)

29. B.B. Orazbayev, Ye.A. Ospanov, K.N. Orazbayeva, V.E. Makhatova, M.K. Urazgaliyeva, A.B. Shagayeva, Development of mathematical models of R-1 reactor hydrotreatment unit using available information of various types, Journal of Physics: Conference Series 1399, 044024, 1-6 (2019) DOI: 10.1088/1742-6596/1399/4/044024

30. B.M. Shumskii, L.A. Zyrianova, Engineering challenges in oil refining and petrochemistry (M.: Chemestry, 256, 2008) 